\title{
Studi Potensi Air Buangan Permukaan Perkotaan Sebagai Sumber Air Irigasi
}

\author{
Binsar SILITONGA ${ }^{1}$
}

\begin{abstract}
Indonesia geographical location $\left(6^{0} L U-11^{0} L S\right)$ causes most of its region experience heavy amount of rainfall. Overflowing rain water is consequently ample in amount, and potentially a great source for irrigation. Both urban and subburbs part of Medan, where some primary livelihood is in agriculture, benefit from this natural event. However the level of availability all year is not certain. Too much in rainy season means flood, and too little means drought in dry season. Farmers normally neglected the importance of storing rain water in rainy season in order to supply the dry season, and thus becomes problem for farmers. How much water can potentially be used for agriculture in urban area, what is the relationship between water amount with soil texture, types of certain-soil-suitable crop, plant growth period. This research aims to analyze and answer this particular question.
\end{abstract}

Kata kunci: air buangan, defenisi irigasi, karakteristik tanah, optimasi, produksi tanaman, tekstur tanah

\section{Latar Belakang}

Kondisi ketersediaan air yang melimpah di Indonesia menjadikan petani sebagai pemakai air menjadi terlena karena beranggapan air akan selalu tersedia dengan cukup setiap waktu ketika diperlukan. Akibatnya tidak ada upaya menampung air untuk kemudian menggunakan air dengan bijak sesuai kebutuhan. Ini bisa terlihat dari berlebihnya air pada petak lahan pertanian sepanjang masa musim tanam. Padahal air dapat diberi dengan cukup saja sesuai kebutuhan dengan memperhatikan tekstur tanah, jenis tanaman dan periode pertumbuhan tanaman.

Kemandirian pangan adalah salah satu pencapaian yang diinginkan oleh Pemerintahan Jokowi-JK. Tentunya keinginan ini tidaklah terlalu muluk bilamana seluruh potensi yang ada dicurahkan untuk membuatnya berhasil.

Indonesia yang termasuk negara agraris besar di dunia tentunya mempunyai konsep perencanaan pembangunan sektor pertanian. Perencanaan pembangunan sektor pertanian yang tersusun dengan baik akan memberi manfaat yang besar yaitu untuk meningkatkan produksi pangan. Peningkatan produksi pangan yang disertai dengan terjaminnya harga jual hasil pertanian akan meningkatkan kesejahteraan masyarakat petani.

Ada beberapa usaha yang telah dan akan tetap dilakukan pemerintah guna mencapai peningkatan produksi pertanian yaitu dengan:

1. Penambahan luas areal pertanian.

2. Adanya bibit pertanian yang unggul.

3. Pemberian subsidi oleh pemerintah kepada petani dalam mendapatkan bibit, pupuk dan obat tanaman.

4. Mengusahakan pertanian dengan mekanisasi.

Bagian 1 dari usaha-usaha untuk peningkatan produksi pertanian seperti yang dituliskan diatas dapat dilakukan dengan memanfaatkan lahan-lahan kosong pada daerah perkotaan yang salah satunya adalah di Kota Medan.

\footnotetext{
${ }^{1}$ Staf Pengajar Teknik Sipil Universitas Katolik Santo Thomas

Anggota HATHI Cabang Sumut

e-mail: binsar_silitong@yahoo.co.id
} 
Kota Medan memiliki luas sekitar $26.510 \mathrm{Ha}\left(265.10 \mathrm{~km}^{2}\right)$ atau setara dengan 3,6\% dari luas keseluruhan Provinsi Sumatera Utara. Batas-batas administasi adalah Sebelah Utara dengan selat Malaka dan sebelah Selatan, Timur, dan Barat dengan Kabupaten Deli Serdang.

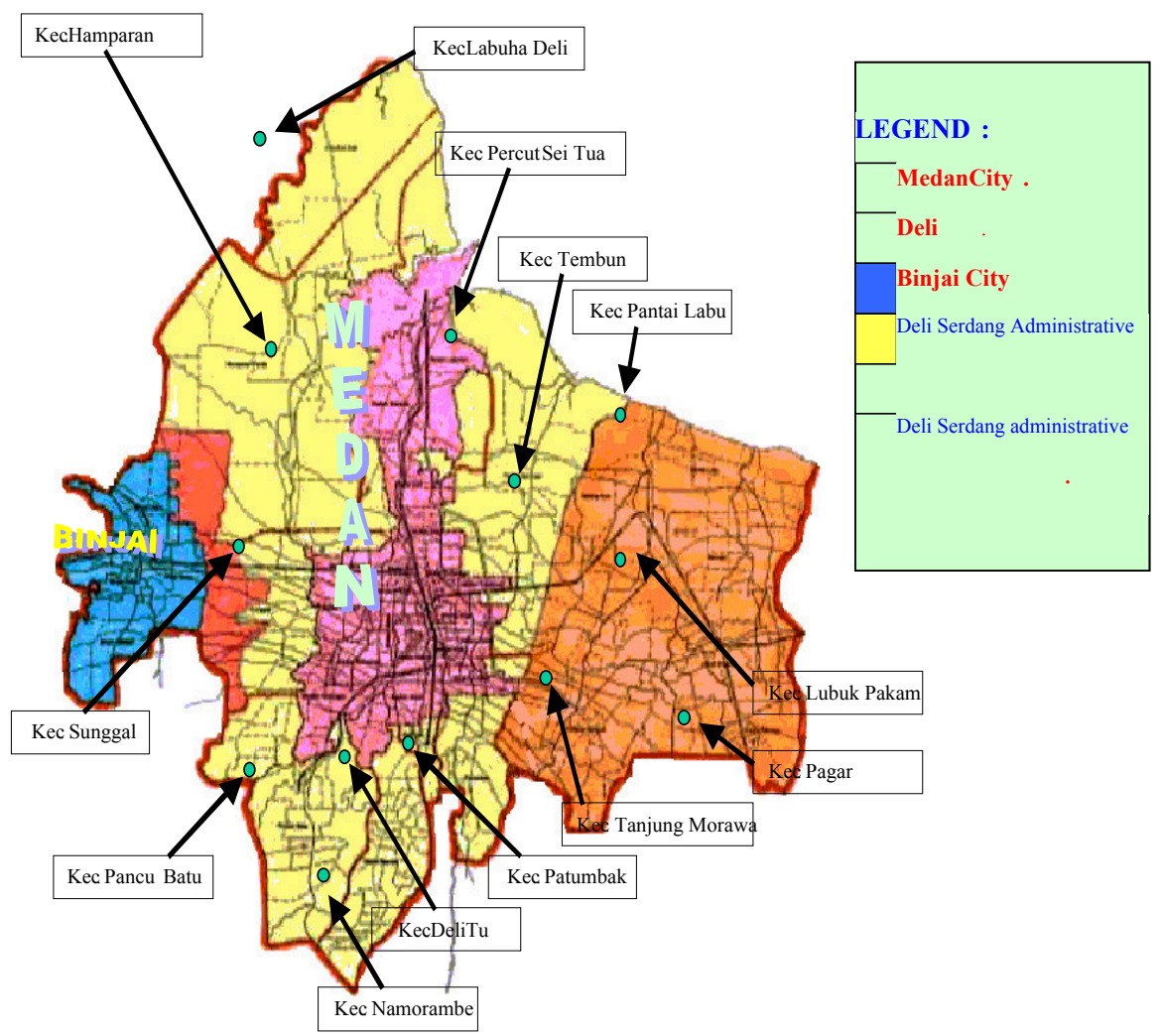

Gambar 1 Batas administratif Kota Medan

Secara geografis terletak pada $2^{0} 27^{\prime}-2^{0} 47^{\prime}$ Lintang Utara dan $98^{0} 35^{\prime}-98^{0} 44^{\prime}$ Bujur Timur. Kota Medan terletak di Pantai Timur Sumatera Utara dengan topografi cenderung miring ke Utara dan berada pada ketinggian 2,5-37,5 meter di atas permukaan laut. Memiliki jumlah populasi penduduk yang permanen 1.941.702 jiwa dan pendatang 566.611 jiwa yang tersebar diseluruh pelosok kota.

Kota Medan memiliki iklim musim laut tropis yang sangat ditentukan oleh arah angin dan senantiasa berubah setiap tahunnya. Perbedaan antara musim penghujan dan musim kemarau sangat jelas dimana musim penghujan terjadi Bulan September - Bulan Februari dan musim kemarau terjadi Bulan Maret Bulan Agustus.

Tahun 2001 menurut data dari Stasiun Poloniasuhu minimum berkisar antara $23,2^{0} \mathrm{C}$ s/d $24,3^{0} \mathrm{C}$ dan suhu maksimum berkisar antara $30,8^{\circ} \mathrm{C}$ s $/ \mathrm{d} 33,2^{\circ} \mathrm{C}$. Sedangkan data dari Stasiun Sampali menyatakan suhu minimum berkisar antara $23,3^{\circ} \mathrm{C}$ s/d $24,1^{\circ} \mathrm{C}$ dan suhu maksimum berkisar antara $31,0^{\circ} \mathrm{C}$ s/d $33,1^{\circ} \mathrm{C}$. Dan kelembapan udara relatif tahunan rerata yang dicatat oleh Stasiun Belawan sebesar $86.13 \%$. Sedang penyinaran matahari tahunan rerata yang dicatat oleh Stasiun Belawan adalah $56.08 \%$. 
Tabel 1 Rekaman Besar Hujan Tahunan (dalam mm) dari Stasiun Polonia

\begin{tabular}{|c|c|c|c|c|c|c|}
\hline Tahun & Jan & Feb & Mar & Apr & Mei & Jun \\
\hline $\mathbf{2 0 1 2}$ & 180,7 & 102,3 & 201,4 & 171,9 & 470,1 & 87,6 \\
\hline $\mathbf{2 0 1 3}$ & 158,4 & 267,2 & 115,7 & 174,1 & 156,8 & 124,8 \\
\hline $\mathbf{2 0 1 4}$ & 20 & 33 & 129 & 140 & 326 & 62 \\
\hline Tahun & Jul & Agt & Sep & Okt & Nov & Des \\
\hline $\mathbf{2 0 1 2}$ & 316,9 & 185 & 287,5 & 431,6 & 274,5 & 146,8 \\
\hline $\mathbf{2 0 1 3}$ & 90,5 & 420,8 & 373,7 & 509,1 & 242,9 & 498,8 \\
\hline $\mathbf{2 0 1 4}$ & 161 & 206 & 285 & 289 & 195 & 300 \\
\hline
\end{tabular}

Tabel 2 Rekaman Besar Hujan Tahunan (dalam mm) dari Stasiun Sampali

\begin{tabular}{|c|c|c|c|c|c|c|}
\hline Tahun & Jan & Feb & Mar & Apr & Mei & Jun \\
\hline $\mathbf{2 0 1 2}$ & 112,2 & 266,7 & 124,4 & 262,3 & 363,7 & 121,8 \\
\hline $\mathbf{2 0 1 3}$ & 118,5 & 199,3 & 73,8 & 150 & 96,4 & 121 \\
\hline $\mathbf{2 0 1 4}$ & 53,8 & 43,8 & 79,4 & 130 & 149,8 & 103,3 \\
\hline Tahun & Jul & Agt & Sep & Okt & Nov & Des \\
\hline $\mathbf{2 0 1 2}$ & 122,6 & 138,3 & 244,4 & 296,6 & 226,2 & 160,8 \\
\hline $\mathbf{2 0 1 3}$ & 172,8 & 213,5 & 180,6 & 345 & 83 & 488,6 \\
\hline $\mathbf{2 0 1 4}$ & 50,1 & 240,8 & 321,4 & 238,8 & 246,9 & 427 \\
\hline
\end{tabular}

Tabel 3 Rekaman Besar Hujan Tahunan (dalam mm) dari Stasiun Belawan

\begin{tabular}{|c|c|c|c|c|c|c|}
\hline Tahun & Jan & Feb & Mar & Apr & Mei & Jun \\
\hline $\mathbf{2 0 1 2}$ & 145 & 71,7 & 299,7 & 97,2 & 383,5 & 38 \\
\hline $\mathbf{2 0 1 3}$ & 101 & 175,9 & 11,2 & 0 & 113,1 & 197,6 \\
\hline $\mathbf{2 0 1 4}$ & 60,7 & 63,7 & 12,7 & 127 & 183,1 & 103,9 \\
\hline Tahun & Jul & Agt & Sep & Okt & Nov & Des \\
\hline $\mathbf{2 0 1 2}$ & 91,1 & 90,1 & 267,1 & 160,7 & 191,6 & 156,9 \\
\hline $\mathbf{2 0 1 3}$ & 242,5 & 263 & 261,4 & 313,6 & 159,9 & 428,5 \\
\hline $\mathbf{2 0 1 4}$ & 96,1 & 317 & 267,1 & 266,3 & 112 & 236,4 \\
\hline
\end{tabular}

\section{Metodologi}

Lokasi penelitian berada di Desa Sari Rejo, Kecamatan Medan Polonia, Kota Medan. Adapun metodologi yang diterapkan dalam penelitian ini adalah kombinasi antara mengumpulkan data primer dan studi kepustakaan yang berhubungan dengan penelitian.

Pengumpulan data meliputi:

a. Pengambilan data tanah dengan penyelidikan lapangan dan laboratorium

b. Luasan petak pertanian

c. Jumlah air yang diberikan

d. Jenis tanaman

Analisa data meliputi:

a. Perhitungan kadar lengas tanah

b. Perhitungan jumlah air minimal yang diberikan sesuai dengan periode hidup tanaman 
c. Perhitungan hasil produksi dengan jumlah air yang diberikan

Untuk studi kepustakaan lebih dititik beratkan pada yang berhubungan dengan irigasi dimana secara defenisi irigasi dapat dinyatakan sebagai upaya pemberian air pada tanah agar tanaman yang tumbuh diatasnya dapat menghasilkan produksi yang maksimal. Dengan demikian ketika berbicara tentang pertanian dan irigasi, maka ada tiga hal yang perlu diperhatikan secara detil yaitu tanah, tanaman dan air.

\section{Air}

Mekanisme terjadinya air di alam semesta ini adalah proses yang saling berulang (cycle) yang dikenal dengan istilah siklus hidrologi (hydrologi cycle). Bermula dari adanya energi panas matahari yang mengenai permukaan bumi. Akibat energi panas ini maka unsur-unsur air yang terdapat pada permukaan tanah maupun permukaan air akan membentuk uap air. Peristiwa ini dikenal dengan evaporasi. Selain itu uap air juga dapat terbentuk akibat transpirasi tanaman, hewan maupun manusia. Uap air ini karena mempunyai massa yang ringan akan naik ke atmosfer dalam bentuk awan. Adanya gerakan angin dan perbedaan tekanan di atmosfer bumi mengakibatkan kumpulan awan ini saling bergerak membentuk kumpulan yang lebih besar yang disebut sebagai awan penyebab hujan (rainy cloud). Pada titik tertentu dimana gaya tekan udara ke atas tidak mampu lagi menahan berat kumpulan awan mengakibatkan massa awan berubah dari uap menjadi titik-titik air. Titik-titik air ini jatu kembali ke permukaan bumi sebagai hujan. Hujan akan sampai ke permukaan yang membentuk aliran permukaan (surface runn off) maupun masuk ke dalam tanah (infiltration) membentuk aliran air tanah (ground water flow). Mekanisme siklus hidrologi ini diperlihatkan pada gambar berikut:

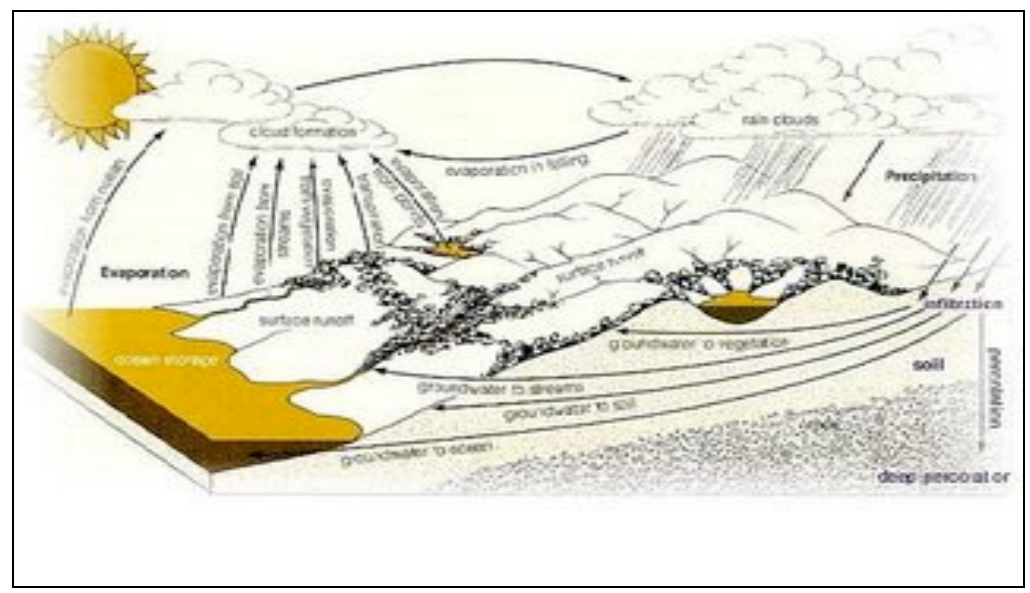

Gambar 2 Bagan Siklus Hidrologi

Didalam irigasi peranan air ini sangat banyak yaitu:

1. Menambah jumlah air didalam tanah sehingga tanah mengandung cairan dalam jumlah yang cukup.

2. Mengatur temperatur tanah sehingga tercipta kondisi yang layak untuk pertumbuhan tanaman.

3. Mencuci tanah dari unsur-unsur yang tidak diharapkan oleh tanaman.

4. Mengurangi pembekuan pada tanah.

5. Melunakkan tanah ketika masa persiapan lahan.

\section{Tanah}

Menurut prinsip pada mekanika tanah (soil mecahanics) yang disebut dengan tanah sesungguhnya disusun oleh butir-butir (solid particel) tanah yang bisa berupa bahan organis maupun bahan non organis dan ruang antar butir (void). 


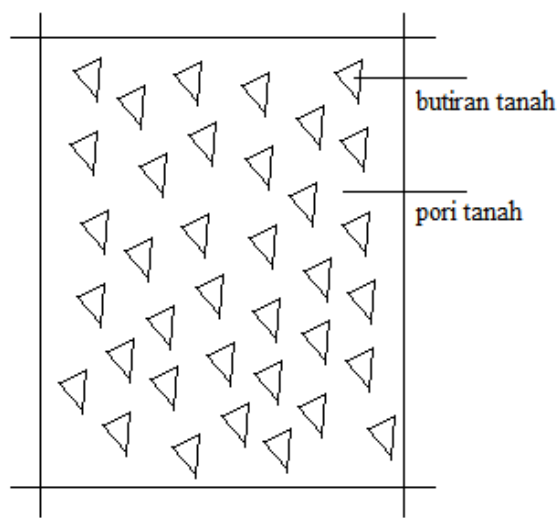

Gambar 3 Komponen Satu Satuan Tanah

Ruang antar butir ini dapat berisi udara (air) dan dapat juga berisi air (water). Kemampuan ruang antar butir untuk dapat diisi ataupun dapat dilewati air yang disebut sebagai kadar air tanah (soil moisture) merupakan bagian yang penting dalam membicarakan hubungan antara jumlah air irigasi yang diberikan berdasarkan tekstur tanah. Untuk melihat hubungan antar keseluruhan komponen tanah tersebut dapat dilihat pada gambar dibawah ini:

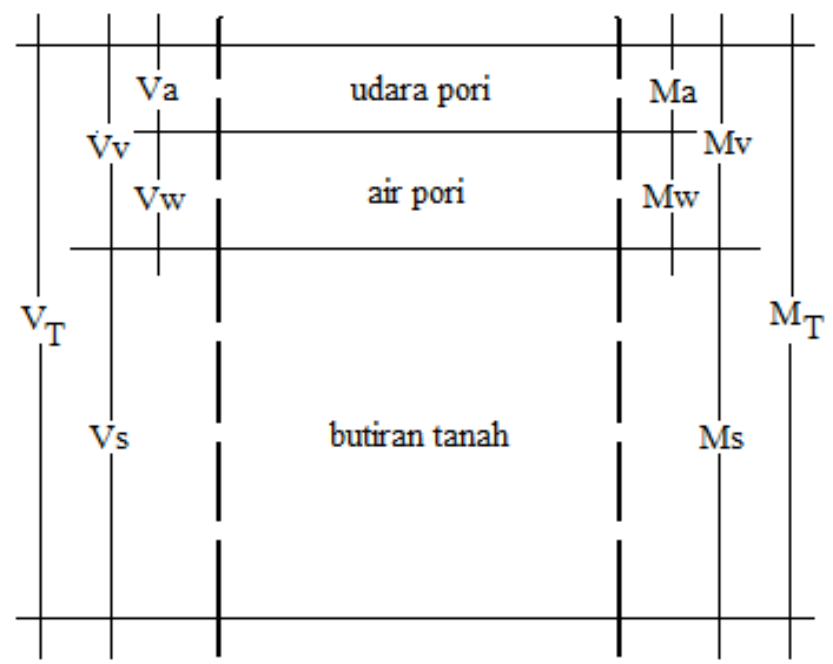

Gambar 4 Hubungan Antara Volume Dan Masa Dari Satu Satuan Tanah

Dari gambar tersebut diatas dapat dinyatakan bahwa jumlah air yang dapat tersedia di dalam tanah dapat dihitung dengan dua cara yaitu:

1. Kebasahan massa tanah (mass soil wetness) yaitu perbandingan antara massa air didalam pori tanah terhadap massa butiran tanah.

$$
\theta_{M}=\frac{M_{W}}{M_{S}}
$$

Persamaan diatas disebut juga persamaan kadar lengas massa tanah

2. Kebasahan volume tanah (volume soil wetness) yaitu perbandingan antara volume air didalam pori tanah terhadap volume butiran tanah. 


$$
\theta_{V}=\frac{V_{W}}{V_{S}}
$$

Persamaan diatas disebut juga persamaan kadar lengas volume tanah

Dari persamaan kadar lengas massa tanah maupun kadar lengas volume tanah akan dikenal beberapa istilah yaitu:

1. Kapasitas jenuh (saturation soil moisture capacity) yaitu ketika seluruh ruang pori tanah berisi air.

2. Kapasitas lapang (fieldsoil moisture capacity) yaitu nilai kapasitas tanah yang terjadi setelah tanah menerima pembasahan oleh air hujan ataupun air irigasi yang biasanya berlangsung 1 hari sampai 3 hari setelah pemberian air pada tanah.

3. Kondisi lengas tanah dimana tanaman tidak mampu untuk menyerap air yang ada didalam tanah baik disebabkan oleh ketidaktersediaan air dalam jumlah cukup didalam tanah maupun karena letak air yang berada jauh diluar wilayah perakaran (root zone). Bila situasi ini terjadi maka tanaman berada pada titik layu permanen (wilting permanent).

4. Kapasitas tersedia (available soil moisture capacity) yaitu nilai kadar lengas tanah yang berada antara fieldsoil moisture capacity dengan wilting permanent.

Kondisi kadar lengas tanah dimana tanaman tidak memungkinkan untuk dapat hidup sama sekali (tanaman mati). Keadaan ini disebut sebagai ultimate wilting point.

\section{Hasil dan Pembahasan}

Dengan memakai besar curah hujan rerata bulanan yang terkecil dari ketiga stasiun akan didapat potensi air limpasan langsung sebesar $1.922 \mathrm{ltr} /$ det. Dengan mengacu kepada kebutuhan air yang menjadi rujukan untuk tanaman padi maupun tanaman palawija sebesar 1 ltr/det/Ha, maka dapat dikatakan bahwa untuk Kota Medan secara jumlah maka air buangan masih sangat potensial dipakai sebagai air irigasi.

Hal ini juga didukung oleh hasil pengujian yang kami lakukan pada daerah penelitian yaitu Kelurahan Sari Rejo Kecamatan Medan Polonia, dimana hasil pengujian terhadap karakteristik tanah di laboratorium didapatkan seperti berikut:

Tabel 4 Berat Jenis dan Kadar Air Tanah Lokasi Studi

\begin{tabular}{|c|c|c|c|}
\hline Lokasi & Tekstur Tanah & Berat Jenis Tanah & Kadar Air Tanah \\
\hline A & Lempung & 2.645 & 54.16 \\
\hline B & Lempung Berpasir & 2.664 & 46.28 \\
\hline C & Lempung Berpasir & 2.681 & 51.43 \\
\hline
\end{tabular}

Sedang jumlah air yang diberikan pada tiap lokasi petak pertanian adalah seperti berikut:

Tabel 5 Jumlah Pemberian Air

\begin{tabular}{|c|l|c|c|}
\hline Lokasi & Tekstur Tanah & Luas $\left(\mathrm{m}^{2}\right)$ & $\begin{array}{c}\text { Jumlah Pemberian Air } \\
(\text { liter/jam) }\end{array}$ \\
\hline A & Lempung & 1450 & 21 \\
\hline B & Lempung Berpasir & 500 & 20 \\
\hline C & Lempung Berpasir & 600 & 22 \\
\hline
\end{tabular}

Hubungan antara jumlah pemberian air dengan hasil produksi pertanian adalah seperti berikut: 
Tabel 6 Jumlah Pemberian Air dan Hasil Produksi

\begin{tabular}{|c|l|c|c|}
\hline Lokasi & Tekstur Tanah & $\begin{array}{c}\text { Jumlah Pemberian Air } \\
\text { (liter/jam) }\end{array}$ & $\begin{array}{c}\text { Produksi } \\
\text { (kaleng) }\end{array}$ \\
\hline A & Lempung & 21 & 1480 \\
\hline B & Lempung Berpasir & 20 & 58 \\
\hline C & Lempung Berpasir & 22 & 85 \\
\hline
\end{tabular}

\section{Kesimpulan}

Dari hasil pengujian dan analisa, maka didapatkan kesimpulan seperti berikut:

1. Potensi air buangan baik yang disebabkan oleh limpasan permukaan dari air hujan cukup untuk menjadi sumber air pertanian di daerah Kota Medan.

2. Jumlah air yang diberikan hendaknya sesuai kebutuhan menurut tekstur tanah.

3. Pemberian air yang cukup ini tidak akan mengurangi hasil produksi pertanian sepanjang perilaku yang diberikan pada tanah dan tanaman adalah sama.

Direkomendasikan untuk melakukan penelitian pada daerah lain yang jenis tanaman pertaniannya bukan padi.

\section{Daftar Pustaka}

Djoko Sasongko, MSc., Ir., (1989) Teknik Sumber Daya Air I, Penerbit Erlangga, Jakarta Suyono Sosrodarsono, Ir., (1989) Hidrologi Untuk Pengairan, Bandung

Doorenbos J. dan Pruitt WO., (1984) Crop Water Requirement, FAO Drainage and Irrigation Paper, Rome

Doorenbos J. dan Kassam AH., (1974) Yield response to Water, FAO Drainage and Irrigation Paper, Rome 